\title{
Effects of the Interactive Web-Based Video "Mon Coeur, Mon BASIC" on Drug Adherence of Patients With Myocardial Infarction: Randomized Controlled Trial
}

Christel Bruggmann ${ }^{1,2,3}$, PharmD, PhD; Julien Adjedj ${ }^{4}$, MD, PhD; Sylvain Sardy ${ }^{5}$ PhD, Prof Dr; Olivier Muller ${ }^{4}$, MD, Prof Dr; Pierre Voirol ${ }^{1,2}$, PhD; Farshid Sadeghipour ${ }^{1,2}, \mathrm{PhD}$, Prof Dr

\footnotetext{
${ }^{1}$ Department of Pharmacy, University Hospital of Lausanne, University of Lausanne, Lausanne, Switzerland

${ }^{2}$ Institute of Pharmaceutical Sciences of Western Switzerland, University of Geneva, Geneva, Switzerland

${ }^{3}$ Department of Pharmacy, University Hospital of Geneva, Geneva, Switzerland

${ }^{4}$ Department of Cardiology, University Hospital of Lausanne, University of Lausanne, Lausanne, Switzerland

${ }^{5}$ Section of Mathematics, University of Geneva, Geneva, Switzerland
}

\section{Corresponding Author:}

Christel Bruggmann, PharmD, PhD

Department of Pharmacy

University Hospital of Geneva

Rue Gabrielle Perret-Gentil 4

Geneva, 1205

Switzerland

Phone: 41796146714

Email: cbruggmann@gmail.com

\section{Abstract}

Background: Secondary prevention strategies after acute coronary syndrome (ACS) presentation with the use of drug combinations are essential to reduce the recurrence of cardiovascular events. However, lack of drug adherence is known to be common in this population and to be related to treatment failure. To improve drug adherence, we developed the "Mon Coeur, Mon BASIC" video. This online video has been specifically designed to inform patients about their disease and their current medications. Interactivity has been used to increase patient attention, and the video can also be viewed on smartphones and tablets.

Objective: The objective of this study was to assess the long-term impact of an informative web-based video on drug adherence in patients admitted for an ACS.

Methods: This randomized study was conducted with consecutive patients admitted to University Hospital of Lausanne for ACS. We randomized patients to an intervention group, which had access to the web-based video and a short interview with the pharmacist, and a control group receiving usual care. The primary outcome was the difference in drug adherence, assessed with the Adherence to Refills and Medication Scale (ARMS; 9 multiple-choice questions, scores ranging from 12 for perfect adherence to 48 for lack of adherence), between groups at 1,3, and 6 months. We assessed the difference in ARMS score between both groups with the Wilcoxon rank sum test. Secondary outcomes were differences in knowledge, readmissions, and emergency room visits between groups and patients' satisfaction with the video.

Results: Sixty patients were included at baseline. The median age of the participants was 59 years (IQR 49-69), and 85\% (51/60) were male. At 1 month, 51 patients participated in the follow-up, 50 patients participated at 3 months, and 47 patients participated at 6 months. The mean ARMS scores at 1 and 6 months did not differ between the intervention and control groups (13.24 vs $13.15,13.52$ vs 13.68 , respectively). At 3 months, this score was significantly lower in the intervention group than in the control group (12.54 vs 13.75; $P=.03$ ). We observed significant increases in knowledge from baseline to 1 and 3 months, but not to 6 months, in the intervention group. Readmissions and emergency room visits have been very rare, and the proportion was not different among groups. Patients in the intervention group were highly satisfied with the video.

Conclusions: Despite a lower sample size than we expected to reach, we observed that the "Mon Coeur, Mon BASIC" web-based interactive video improved patients' knowledge and seemed to have an impact on drug adherence. These results are encouraging, and the video will be offered to all patients admitted to our hospital with ACS.

Trial Registration: ClinicalTrials.gov NCT03949608; https://clinicaltrials.gov/ct2/show/NCT03949608 
(J Med Internet Res 2021;23(8):e21938) doi: 10.2196/21938

\section{KEYWORDS}

acute coronary syndrome; eHealth; drug adherence; mHealth; mobile phone

\section{Introduction}

Cardiovascular disease is a major cause of morbi-mortality in Europe, with a substantial contribution from acute coronary syndrome (ACS) [1]. Secondary prevention strategies, such as risk factor control through lifestyle modifications and the use of medication combinations, have greatly reduced the recurrence of ACS [2]. European guidelines have been developed to enhance evidence-based medicine prescriptions for patients with myocardial infarction (MI) [3,4], and we previously showed that physicians at our hospital in Switzerland predominantly issued prescriptions of this type [5]. However, poor patient self-adherence to cardiac medications has been documented worldwide [6-8] and has been associated with increased morbi-mortality [9-11]. The discontinuation of antiplatelet drugs has been related to fatal consequences such as stent thrombosis, particularly soon after ACS onset [12].

Poor drug adherence is related to many factors associated with health care systems (eg, cost, access to care), socioeconomics (ie, poverty), therapy (ie, treatment complexity, cost), and patients (ie, health literacy, willingness to change, knowledge, education) [13]. In Switzerland, the health care system offers high-quality care to all residents, and less social inequality exists than in other countries; we thus believe that patient adherence in this country is more likely related to treatment and patient factors. The provision of sufficient and effective information to patients with chronic diseases has been shown to increase patient satisfaction [14], reduce psychological distress [15], enhance patients' perceived control [16], and improve patient adherence to medication prescriptions [13]. Thus, the offering of such information and knowledge to all patients with ACS is very important.

Various interventions have been shown to promote drug adherence in the context of cardiovascular health. These strategies range from the simple, such as the distribution of written material about medications [17] and the regular mailing of informational letters $[18,19]$, to multifaceted interventions (eg, medication reconciliation, therapeutic education) involving clinical pharmacists $[20,21]$ and nurses specialized in therapeutic education [22].

The length of hospital stays after MI has shortened in recent years, which has reduced the number of opportunities to inform patients about their disease during hospitalization. Cardio-rehabilitation (CR) centers are meant to fill this gap, but not all patients participate in CR programs. In addition, depending on the type of program chosen (ie, stationary or ambulatory), the objective may be oriented more toward cardiovascular reeducation than to patient education. Moreover, very few sessions are devoted to educating patients about their drug treatments.

Different kinds of mobile health (mHealth) technologies have been developed to support cardiovascular health, like eHealth diaries [23], apps supporting cardiac rehabilitation [24,25], and complete e-learning platforms [26]. However, none of these technologies were available in French, and only a few studies have evaluated the impact of mHealth technologies on therapeutic adherence [27,28]. As we were convinced that mHealth technologies have an impact on drug adherence, we wanted to test it with our study. Therefore, we developed a new approach using a video tool for the provision of information and patient education. The tool we developed is interactive, web-based, smartphone- and tablet-compatible, and it is designed to be offered to patients with ACS during their hospital stays. We tested whether this tool has impacts on drug adherence and patient knowledge after ACS. Our study is therefore expected to fill some important gaps in the current literature.

\section{Methods}

\section{Study Design and Population}

The Secondary Prevention of ACS With Beta-Blockers, Antiaggregants, Statins, Angiotensin-Converting Enzyme Inhibitors, and Risk Factor Control (BASIC) study was a single-center randomized trial. The objective of the study was to assess if a new web-based and interactive video could increase long-term drug adherence, as well as the knowledge of the patients about their disease and their current medications, in patients admitted in hospital for an ACS.

The patients were screened between February 1 and September 1, 2019, on admission to the University Hospital of Lausanne. The intervention for this study was added to usual care, in which all patients with ACS watched a 20-minute video called ELIPS during their hospital stays [29]. ELIPS explains acute infarction, acute care, and the drugs prescribed. Patients also received a booklet about coronary artery disease. All patients admitted to our hospital for ACS are encouraged to participate in a CR program after discharge; the program chosen depends on each patient's willingness and home location. Two types of programs are offered (a 3-week stationary program and an ambulatory program), and both are reimbursed by health insurance.

Participants eligible for the study were men and women older than 18 years who were diagnosed with ST-segment elevation myocardial infarction (STEMI) or non-ST-segment elevation myocardial infarction (NSTEMI) treated with percutaneous coronary intervention (PCI). Other requirements were total discernment capacity; possession of a digital tablet, smartphone, or home computer; and satisfactory French language skills. Exclusion criteria were the inability to follow the study procedure (eg, due to language problems, psychological disorders, dementia), refugee claimant status, homelessness or incarceration (because of the impossibility of contacting such individuals after discharge), and life expectancy $<6$ months due to another disease.

Eligible participants were randomized to the intervention and control groups using a 1:1 allocation ratio after providing oral 
and written informed consent. The randomization was conducted by a clinical study specialist who was not involved in the study. The randomization process was made by week and block of 4 . Each week was randomized as intervention or control in order to avoid having two patients in different groups next to each other in the intermediate care unit.

\section{"Mon Coeur, Mon BASIC" Web-Hosted Video}

"Mon Coeur, Mon BASIC" is an interactive web-hosted video that is smartphone- and tablet-compatible. It is freely available online [30]. It is a simple animated cartoon (Figure 1) with narration in French. It consists of three parts providing information about heart function and the physiopathology of
ACS, acute care for ACS (coronarography and PCI), and the medications prescribed after ACS (usefulness and side effects), with a total length of about 15 minutes. The viewer can click on the video using a mouse or finger to obtain information about a particular point or to jump directly to another subject. The video was developed by a working group consisting of a pharmacist, a graphic designer, a specialist in patient communication, and a cardiologist. It was designed using Illustrator and InDesign (both from Adobe Inc, San José, California), and the interactivity was created using Storyline 360 (Articulate, New York). It was tested with several patients, and all bugs were eliminated before the beginning of the study. 
Figure 1. Screenshots from the "Mon Coeur, Mon BASIC" video.
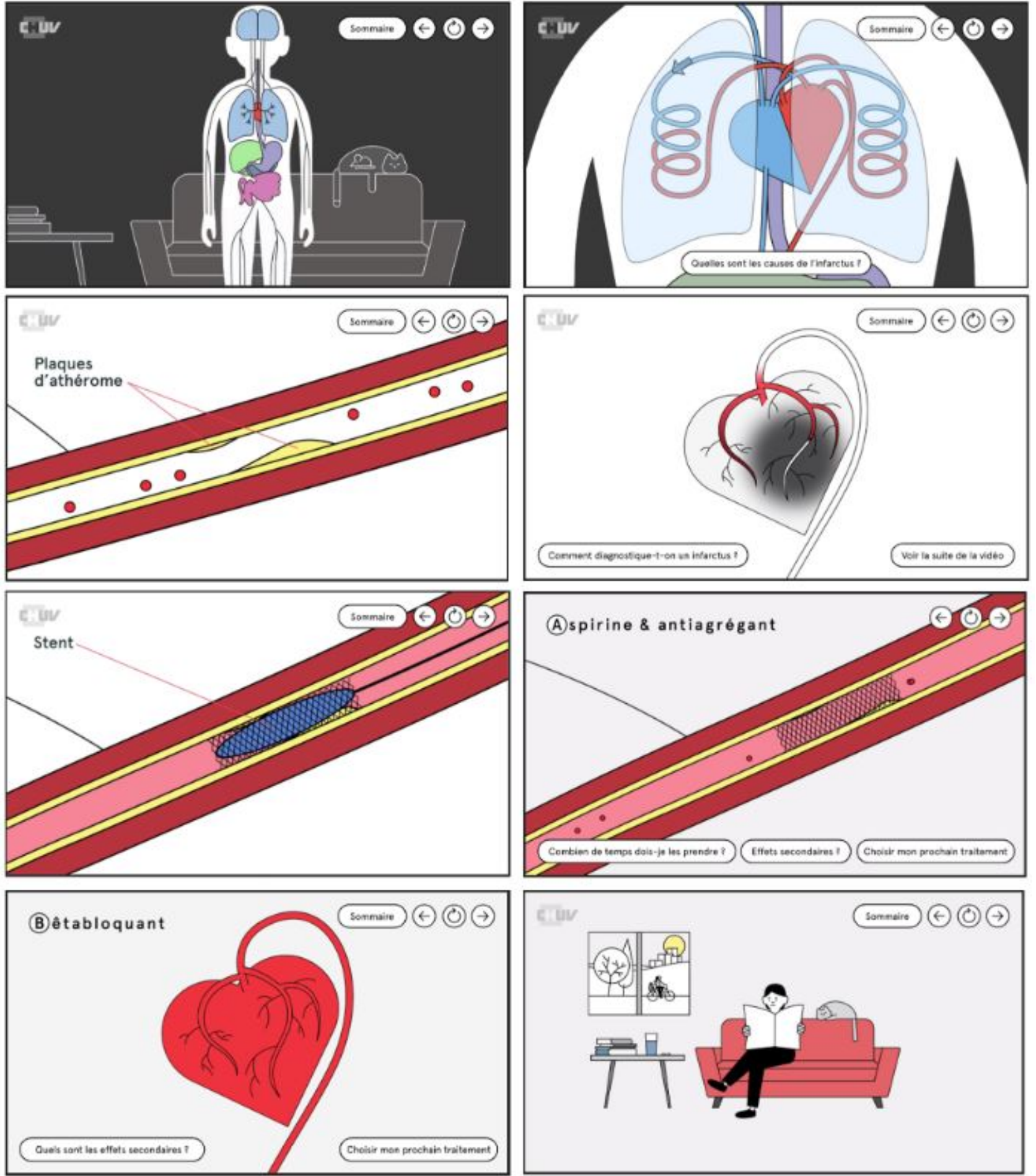

\section{Intervention and Control Condition}

The pharmacist participating in the study met all patients in the intervention group during their hospital stays and gave each of them a medication card with his or her current prescriptions (Multimedia Appendix 1). The medication card contained all the medications currently prescribed to the patient, classified by type of medication according to the acronym BASIC for Beta-blocker, Antiaggregant, Statin, angiotensin-converting enzyme Inhibitor, and Control of risk factors (ie, smoke cessation, limitation of fatty meals, etc), and was the size of a credit card. She then connected to the e-learning website on the patient's tablet or smartphone and created a shortcut. Tablets from the institution were lent to patients with no tablet, smartphone, or computer. The pharmacist asked the patients to watch the video at their convenience. After the patients had watched the video, the pharmacist visited to answer questions and distribute study questionnaires (described below). The postvideo visit was short, and the aim of the visit was to check if the patients had watched the video and to answer patients' questions if they had any. The duration of this visit was around 10 minutes per patient. 
The control group received usual care. In usual care, the patient has no meeting with the pharmacist at all, and the information about medications and the disease are provided by the nurses and the physician in charge of the patient during hospitalization. All the patients (in control and intervention group) also watched a short film developed in the Geneva University Hospitals [29]. For the purpose of the study, the pharmacist only met patients randomized to the control group to give them the study questionnaires.

\section{Primary Outcome}

The primary outcome was the difference in medication adherence between groups at 1, 3, and 6 months after ACS for the assessment of postdischarge treatment initiation, treatment implementation in daily life, and long-term treatment persistence, respectively. Adherence was assessed using the Adherence to Refills and Medication Scale (ARMS; Multimedia Appendix 2). This self-report questionnaire was chosen due to its strong internal consistency (Cronbach $\alpha=.814$ ), good correlation with other subjective and objective measures, and validation for use with patients with coronary heart disease [32]. It consists of 12 items assessing adherence to taking medication $(n=8)$ and refilling prescriptions $(n=4)$. The questionnaire is made up of affirmations that can be answered with "none of the time," "some of the time," "most of the time," or "all of the time," varying from 1 to 4 points, respectively. Final scores range from 12 (most adherence) to 48 (least adherence) and can be treated as continuous measures or dichotomized as 12 and $>12$. We translated the validated English version of the ARMS into French according to guidelines developed for health care research [33].

\section{Secondary Outcomes}

The first secondary outcome was the difference in ACS-related knowledge (basics of heart function, ACS pathophysiology, and usefulness of prescribed medications) between groups, assessed using a questionnaire developed specifically for this study (Multimedia Appendix 3). The questionnaire has 9 items, and scores range from 0 to 9 (most knowledge). The questionnaire was given to the intervention group as a pretest (before the video viewing) and posttest (after viewing), to the control group 1 day after study inclusion, and to all participants at 1,3 , and 6 months. We also assessed whether the groups differed in a composite measure of cardiovascular mortality, first occurrence of reinfarction, recurrence of ACS, cardiovascular death, and readmission and emergency room visitation over the 6-month study period. Finally, we assessed patients' satisfaction with the video using a questionnaire of 11 multiple-choice questions.

\section{Data Collection}

Most baseline data (eg, demographic characteristics, laboratory values, and vital parameters on day 2 after ACS; ACS type and therapeutic strategy; cardiovascular risk factors; drug prescribed at discharge) were collected from computerized patient records generated during hospitalization. Other data were collected through patient interviews; they included patients' email addresses, educational levels (graduation of primary, secondary, or tertiary school), employment statuses (full time, part time, retired, or unemployed), spoken French levels (native, near native, highly proficient, very good working knowledge, or basic communication skills), general practitioners' names, types of device used at home (smartphone, tablet, or computer), information and communications technology (ICT) use levels (low: short message service or telephone only, medium: also maps and basic online research, or high: many applications in daily life), and health literacy scores, assessed with the validated French translation of the Functional, Communicative and Critical Health Literacy (FCCHL) tool [34]. FCCHL scores range from 14 (least literacy) to 70 (most literacy). All data were collected and managed using REDCap (Research Electronic Data Capture) tools hosted in the University Hospital of Lausanne [35,36]. REDCap is a secure, web-based software platform designed to support data capture for research studies.

An email with a link to the study questionnaires (hosted by REDCap) was sent to the participants at 1,3, and 6 months after study inclusion. For participants who did not provide any email address, the questionnaires were mailed with postage-paid return envelopes.

\section{Statistical Analysis}

An intention-to-treat analysis including all study participants was performed. The characteristics of patients randomized to the intervention and control groups were expressed as medians with 25th and 75th percentiles for continuous variables, and as numbers and percentages for categorical variables. They were compared using the Pearson chi-square test for categorical variables and the $t$ test for continuous variables.

The ARMS scores at 1,3, and 6 months were compared between groups using the Wilcoxon rank sum test. This test was also used to compare pretest and posttest knowledge scores and those at 1,3 , and 6 months between groups. The Wilcoxon rank sum test for paired data was used to assess differences in knowledge within groups between study timepoints. Descriptive statistics (numbers and percentages) were calculated for the composite outcome, satisfaction scores, and video reuse. The level of significance for all analyses was set at two-sided $\alpha<.05$. All analyses were performed using Stata software (version 14; StataCorp, College Station, Texas).

We performed a power analysis to estimate the sample size required to detect a significant difference in medication adherence between the intervention and control groups. We based the calculation on the mean ARMS score of 16.32 (SD 4.06) for chronically ill patients [32]. We determined that a sample of 128 patients (64 per group) was needed to detect a difference of $0.5 \mathrm{SD}$ (ie, 2.03) between the intervention and control groups at a two-sided 5\% significance level with a power of 0.8 and an allocation ratio of 1:1. Assuming 10\% loss to follow-up, the target sample size was 142 patients. Based on our hospital's annual admission rate of 500 patients with NSTEMI and 300 patients with STEMI, we initially believed that study enrollment would be completed within 20 weeks, but because many patients were discharged before we could conduct baseline assessment, and an unexpectedly large number of patients refused to participate, we extended the enrollment period to 37 weeks. However, because the investigator was not available for a longer period of time than planned, we had to 
terminate the study before the target sample size had been reached. The results presented in this article must therefore be interpreted with caution because the study was underpowered.

\section{Ethical Considerations}

This study was approved by the local ethics committee (Commission cantonale d'éthique de la Recherche sur l'être humain du Canton de Vaud; number 2018-02223) and registered at ClinicalTrials.gov (number NCT03949608). It complied with the principles of good clinical practice and the Declaration of Helsinki.

\section{Results}

\section{Study Population and Baseline Characteristics}

In total, 170 patients were screened during the study period, and 125 patients were asked to participate (Figure 2). Of these, $31(24.8 \%)$ patients declined participation, and $26(20.8 \%)$ were transferred to district hospitals shortly thereafter and were not enrolled. We randomized 68 patients to the control $(n=30)$ and intervention $(n=38)$ groups. Of these, 8 patients were transferred unexpectedly to district hospitals, did not watch the video, or did not complete the baseline questionnaires; thus, the final baseline sample consisted of 60 patients (33 in the intervention group and 27 in the control group) with complete baseline data. An additional 21 of the 68 randomized patients (31\%) did not complete the follow-up questionnaires.

Figure 2. Patient flowchart within the study period. ACS: acute coronary syndrome; CABG: coronary artery bypass grafting; PCI: percutaneous coronary intervention.

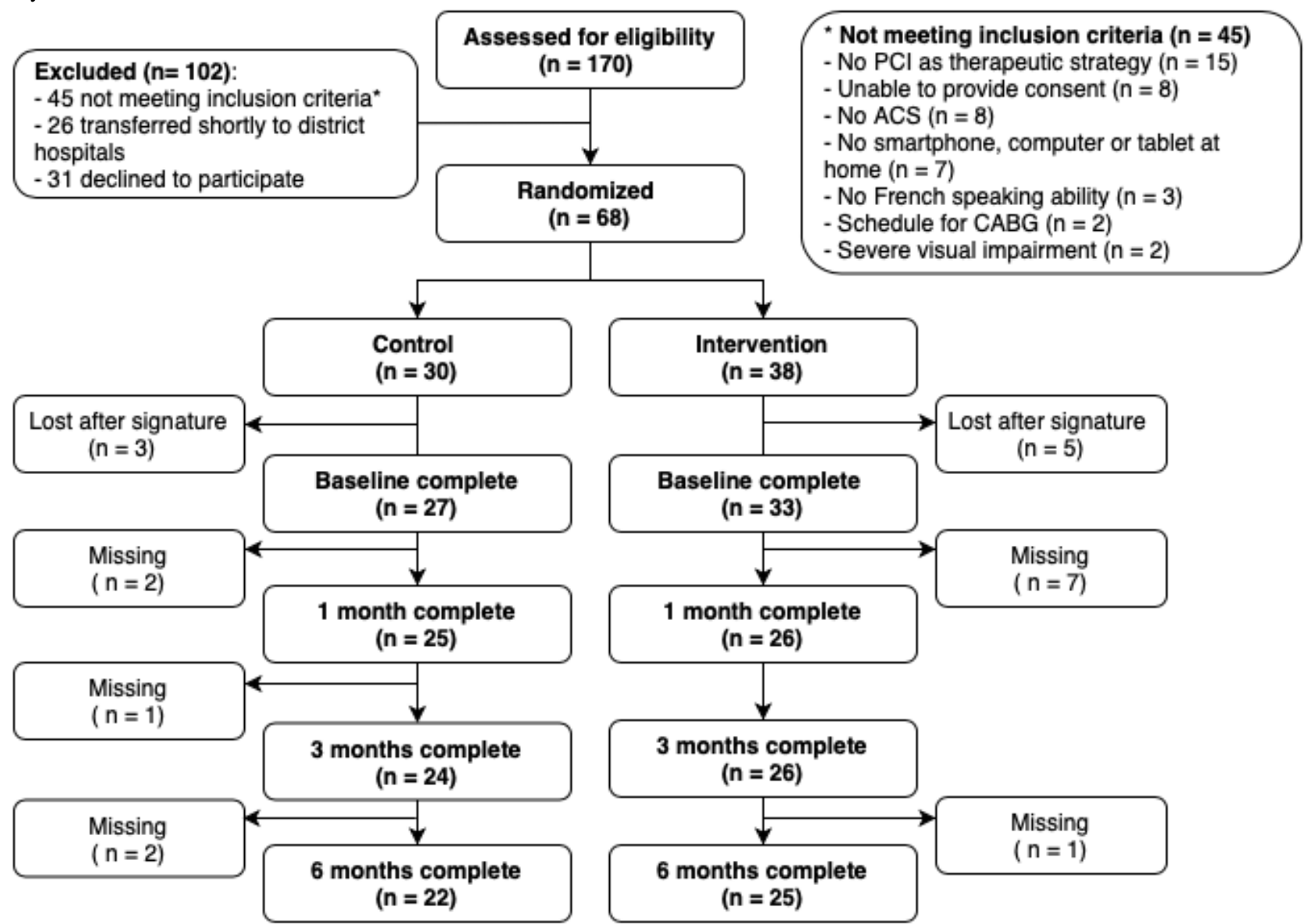

The median age of the 60 patients included was 59 years; $85 \%$ $(51 / 60)$ of the patients were men, $19 \%(11 / 59)$ had diabetes, and about $45 \%(25 / 56)$ were active smokers (Table 1). Patients in the control group were slightly older and more often retired than patients in the intervention group were. They also had more comorbidities and more often had NSTEMI than did patients in the intervention group. However, the groups were well matched, with no significant difference in baseline characteristics. 
Table 1. Baseline patient characteristics ( $\mathrm{N}=60)$. Categorical data are presented as $\mathrm{n}(\%)$ and continuous data are presented as median (interquartile range). $P$ values were estimated with the chi-square test for categorical variables and $t$ test for continuous variables.

\begin{tabular}{|c|c|c|c|c|}
\hline Characteristic & Overall $(\mathrm{N}=60)$ & Intervention $(\mathrm{n}=33)$ & Control (n=27) & $P$ value \\
\hline \multicolumn{5}{|l|}{ Demographic characteristics } \\
\hline Sex (male), n (\%) & $51(85)$ & $27(82)$ & $24(89)$ & .45 \\
\hline Age (years), median (IQR) & $59(49-69)$ & $56(46-68)$ & $62(56-71)$ & .10 \\
\hline Civil status, n (\%) & & & & .70 \\
\hline Single & $10(17)$ & $4(12)$ & $6(22)$ & \\
\hline Married & $36(60)$ & $20(61)$ & $16(59)$ & \\
\hline Divorced & $11(18)$ & $7(21)$ & $4(15)$ & \\
\hline Widowed & $3(5)$ & $2(6)$ & $1(4)$ & \\
\hline Education level, n (\%) & & & & .54 \\
\hline Compulsory school & $8(13)$ & $6(18)$ & $2(7)$ & \\
\hline High school, internship & $28(47)$ & $15(45)$ & $13(48)$ & \\
\hline University of applied sciences & $8(13)$ & $3(9)$ & $5(18.5)$ & \\
\hline Bachelor's degree & $5(8)$ & $2(6)$ & $3(11.1)$ & \\
\hline Master's degree or more & $11(18)$ & $7(21)$ & $4(14.8)$ & \\
\hline Employment, n (\%) & & & & .17 \\
\hline Full time & $29(48)$ & $20(61)$ & $9(33.3)$ & \\
\hline Part time & $7(12)$ & $2(6)$ & $5(19)$ & \\
\hline Retired & $20(33)$ & $9(27)$ & $11(41)$ & \\
\hline Unemployed & $4(7)$ & $2(6)$ & $2(7)$ & \\
\hline French speaking level, n (\%) & & & & .66 \\
\hline Native & $48(80)$ & $26(79)$ & $22(81)$ & \\
\hline Near native & $12(20)$ & $7(21)$ & $5(19)$ & \\
\hline \multicolumn{5}{|l|}{ Device type, n (\%) } \\
\hline Computer & $55(92)$ & $30(91)$ & $25(93)$ & .81 \\
\hline Smartphone & $51(85)$ & $28(85)$ & $23(85)$ & \\
\hline Tablet & $38(63)$ & $24(73)$ & $14(52)$ & \\
\hline ICT $^{\mathrm{a}}$ use level, $\mathrm{n}(\%)$ & & & & .37 \\
\hline Low & $12(20)$ & $7(21)$ & $5(19)$ & \\
\hline Medium & $9(15)$ & $3(9)$ & $6(22)$ & \\
\hline High & $39(65)$ & $23(70)$ & $16(59)$ & \\
\hline Health literacy $\left(\mathrm{FCCHL}^{\mathrm{b}}\right)$ score, median (IQR) & $49(44.5-54)$ & $50(44-54)$ & $48(45-54)$ & .95 \\
\hline \multicolumn{5}{|l|}{ Cardiovascular risk factors } \\
\hline Smoking status ${ }^{\mathbf{c}}, \mathbf{n}(\%)$ & & & & .13 \\
\hline Active & $25(45)$ & $14(47)$ & $11(42)$ & \\
\hline Former & $17(30)$ & $9(30)$ & $8(31)$ & \\
\hline Diabetes $^{\mathrm{d}}, \mathrm{n}(\%)$ & $11(19)$ & $5(16)$ & $6(22)$ & .52 \\
\hline Hypertension, n (\%) & $32(53)$ & $17(52)$ & $15(56)$ & .76 \\
\hline Dyslipidemia $^{\mathrm{e}}, \mathrm{n}(\%)$ & $34(59)$ & $23(72)$ & $11(42)$ & .02 \\
\hline Alcohol consumption ${ }^{\mathrm{f}}, \mathrm{n}(\%)$ & $5(10)$ & $3(9)$ & $2(11)$ & .89 \\
\hline Family history of $\mathrm{ACS}^{\mathrm{g}, \mathrm{h}}, \mathrm{n}(\%)$ & $24(44)$ & $15(47)$ & $9(41)$ & .67 \\
\hline
\end{tabular}




\begin{tabular}{|c|c|c|c|c|}
\hline Characteristic & Overall $(\mathrm{N}=60)$ & Intervention $(\mathrm{n}=33)$ & Control $(n=27)$ & $P$ value \\
\hline Overweight, n (\%) & $37(62)$ & $21(64)$ & $16(59)$ & .73 \\
\hline Drugs used chronically before ACS, median (IQR) & $1(0-3)$ & $0(0-2)$ & $2(1-3)$ & .12 \\
\hline \multicolumn{5}{|l|}{ ACS type, $n(\%)$} \\
\hline STEMI ${ }^{\mathrm{i}}$ & $52(87)$ & $31(94)$ & $21(78)$ & .07 \\
\hline NSTEMI $^{\mathrm{j}}$ & $8(13)$ & $2(6)$ & $6(22)$ & \\
\hline LVEF $^{k}$ evaluation during hospitalization, n (\%) & & & & .23 \\
\hline$<40 \%$ & $6(10)$ & $2(6)$ & $4(15)$ & \\
\hline$\geq 40 \%$ & $54(90)$ & $31(94)$ & $23(85)$ & \\
\hline \multicolumn{5}{|l|}{ Discharge } \\
\hline Total length of stay (days), median (IQR) & $3(2-4)$ & $3(2-4)$ & $3(2-4)$ & .70 \\
\hline Destination after university hospital discharge, $n(\%)$ & & & & .71 \\
\hline Home & $40(67)$ & $23(70)$ & $17(63)$ & \\
\hline Cardio-rehabilitation center & $2(3)$ & $1(3)$ & $1(4)$ & \\
\hline District hospital & $17(28)$ & $8(24)$ & $9(33)$ & \\
\hline Another in-hospital department & $1(2)$ & $1(3)$ & $0(0)$ & \\
\hline Drugs prescribed at discharge, median (IQR) & $6(6-7.5)$ & $6(6-7)$ & $7(5-9)$ & .53 \\
\hline \multicolumn{5}{|l|}{ Prescriptions at discharge, $n(\%)$} \\
\hline Beta-blocker & $53(88)$ & $27(82)$ & $26(96)$ & .08 \\
\hline $\mathrm{ACEI}^{1}$ & $55(92)$ & $30(91)$ & $25(93)$ & .81 \\
\hline Statin & $59(98)$ & $33(100)$ & $26(96)$ & .27 \\
\hline Aspirin & $60(100)$ & $33(100)$ & $27(100)$ & $\mathrm{N} / \mathrm{A}^{\mathrm{m}}$ \\
\hline $\mathrm{P} 2 \mathrm{Y}_{12}$ inhibitor & $60(100)$ & $33(100)$ & 27 (100) & N/A \\
\hline
\end{tabular}

${ }^{\mathrm{a}} \mathrm{ICT}$ : information and communications technology.

${ }^{b}$ FCCHL: Functional, Communicative and Critical Health Literacy tool (French translation).

${ }^{\mathrm{c}}$ Four missing values ( 3 in the intervention group, 1 in the control group).

${ }^{\mathrm{d}}$ One missing value (intervention group).

e Two missing values ( 1 in each group).

${ }^{\mathrm{f}}$ Nine missing values ( 1 in the intervention group, 8 in the control group).

${ }^{\mathrm{g}} \mathrm{Six}$ missing values (1 in the intervention group, 5 in the control group).

${ }^{\mathrm{h}} \mathrm{ACS}$ : acute coronary syndrome.

${ }^{\mathrm{i}}$ STEMI: ST-segment elevation myocardial infarction.

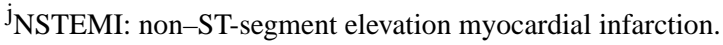

${ }^{\mathrm{L}} \mathrm{LVEF}$ : left ventricular ejection fraction.

${ }^{1} \mathrm{ACEI}$ : angiotensin-converting enzyme inhibitor.

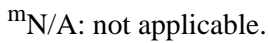

\section{Primary Outcome: ARMS Score}

At 1 month, the mean ARMS score did not differ significantly between the intervention and control groups $(13.15,95 \% \mathrm{CI}$ 12.56-13.74 and 13.24, 95\% CI 12.52-13.96, respectively; $P=.99)$. At 3 months, the ARMS score was significantly lower in the intervention group than in the control group (12.54, 95\%

CI $12.08-13.00$ vs $13.75,95 \%$ CI $12.74-14.76 ; P=.03)$. At 6 months, this score did not differ between the intervention and control groups $(13.52,95 \%$ CI $12.63-14.41$ and $13.68,95 \%$ CI 12.96-14.76, respectively; $P=.33$; Figure 3 ). The median ARMS score increased from 1 to 6 months in the control group but remained more stable (at $\sim 12$ ) in the intervention group, despite a change in distribution. 
Figure 3. ARMS scores at 1,3, and 6 months. In the box plots, the boundary of the box closest to zero indicates the 25th percentile, the line within the box represents the median, and the boundary of the box farthest from zero indicates the 75th percentile. Whiskers above the box indicate the 90 th percentile. Points above the whiskers represent the outliers outside the 90th percentile. The $P$ values represent statistics made with the nonparametric Wilcoxon test. $\mathrm{n}$ represents the number of participants per group. ARMS: Adherence to Refills and Medication Scale.

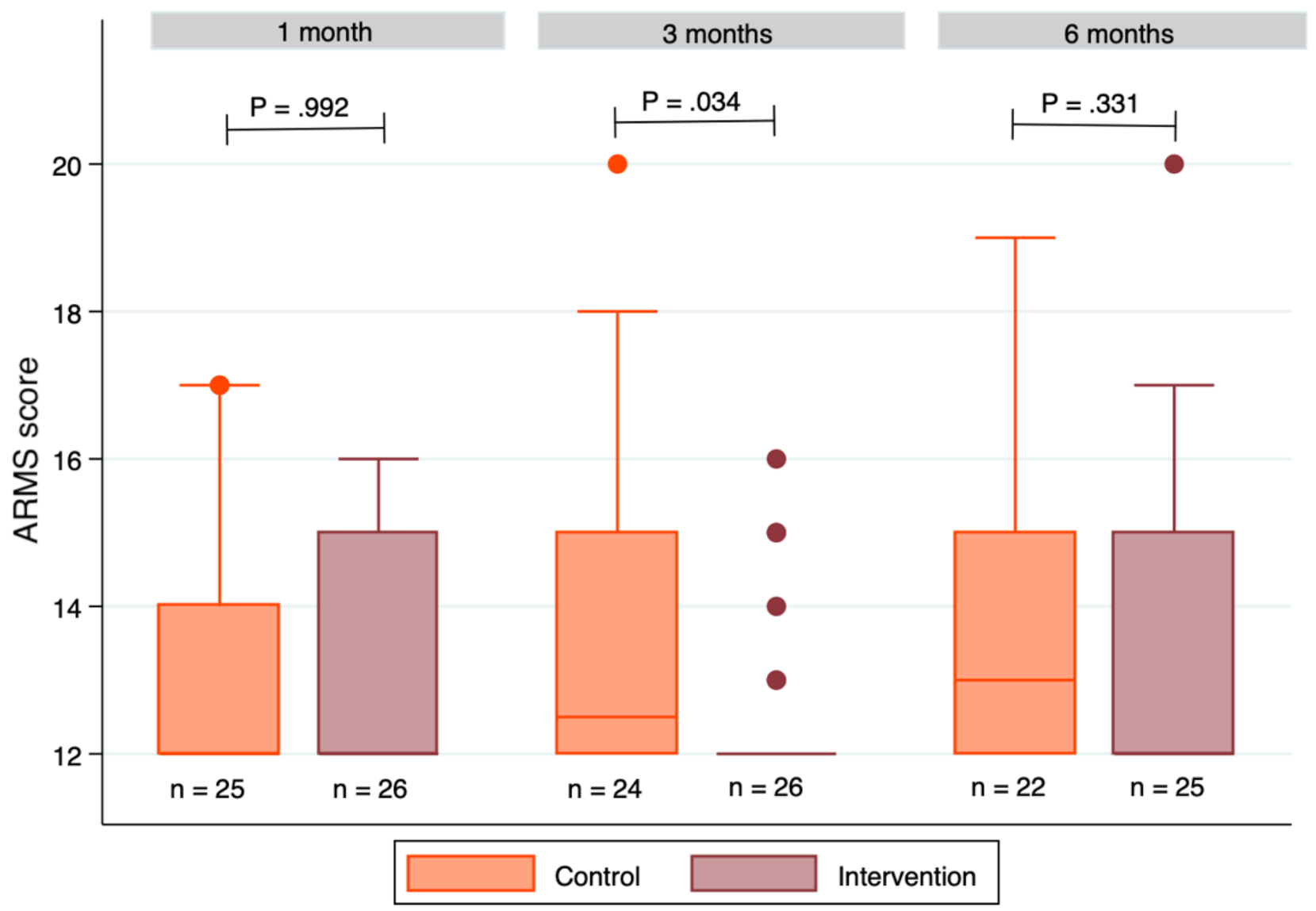

Of 13 participants whose ARMS scores increased between 1 and 3 months, 10 were in the intervention group, and 3 were in the control group. In 7 (54\%) cases, scores increased because patients provided different responses to the last item about prescription refills (Multimedia Appendix 2).

\section{Secondary Outcomes}

\section{Knowledge Score}

The mean knowledge score did not differ significantly between the intervention and control groups at baseline or at 1,3 , or 6 months $(7.22,95 \%$ CI 6.64-7.81 and 7.03, 95\% CI 6.46-7.60; $8.19,95 \%$ CI 7.66-8.72 and 7.72, 95\% CI 7.06-8.38; 8.36, $95 \%$ CI 8.03-8.69 and 8.00, 95\% CI 7.44-8.56; and 8.04, 95\% CI 7.54-8.54 and 7.72, 95\% CI 7.00-8.45, respectively; all $P \mathrm{~s}>.05$; Figure 4). Within each group, knowledge increased from baseline to 6 months; increases were significant in the intervention group between baseline and 3 months, but not at 6 months (Table 2). 
Figure 4. Knowledge scores (0-9) at baseline (pretest), 1 day after ACS (posttest), and 1, 3, and 6 months after ACS. In the box plots, the boundary of the box closest to zero indicates the 25th percentile, the line within the box represents the median, and the boundary of the box farthest from zero indicates the 75th percentile. Whiskers above the box indicate the 90th percentile. Points above the whiskers represent the outliers outside the 90th percentile. $n$ represents the number of participants per group. ACS: acute coronary syndrome.

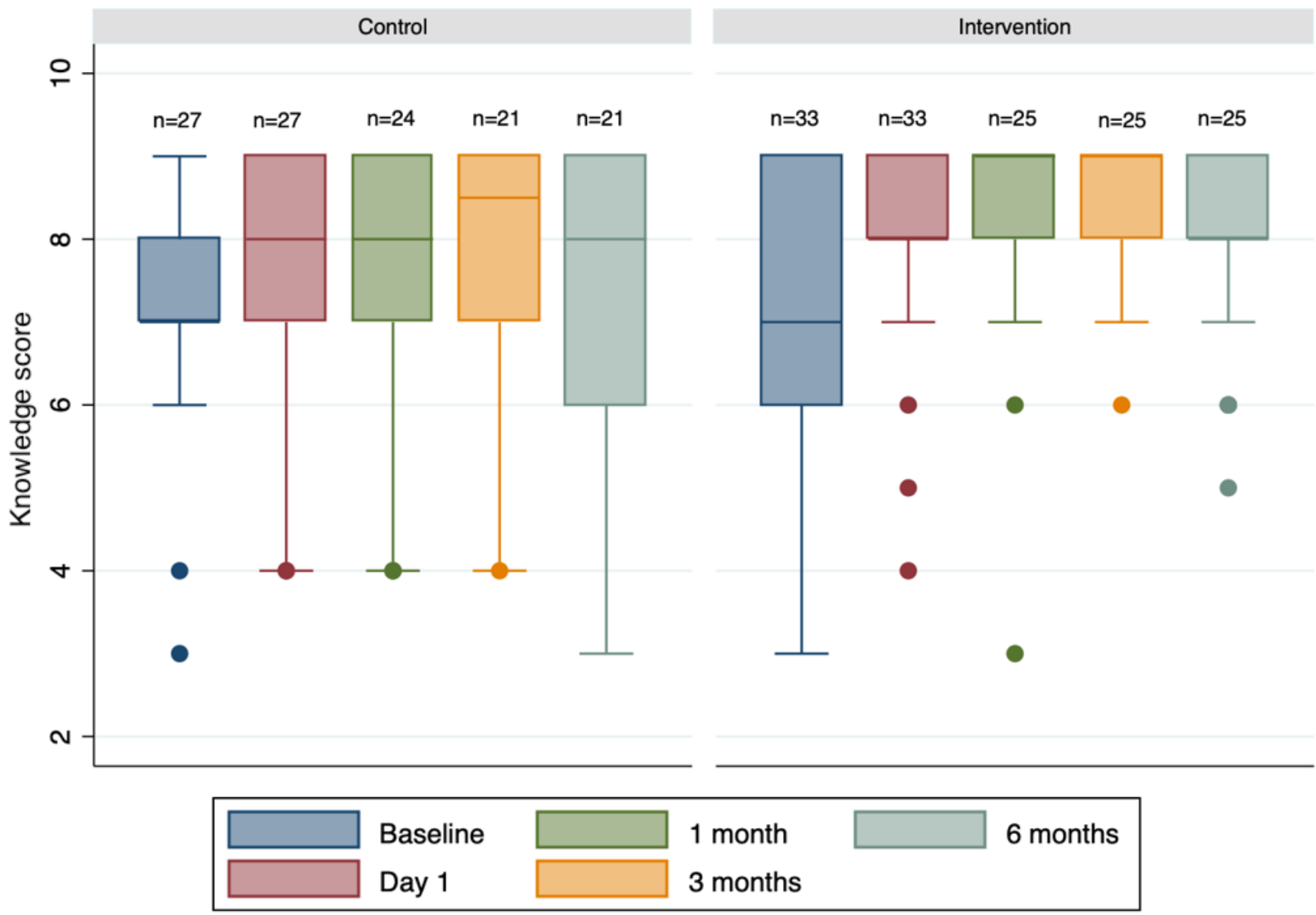

Table 2. Differences in knowledge scores from baseline.

\begin{tabular}{|c|c|c|c|c|}
\hline Timepoint & Control, median $(95 \% \mathrm{CI})$ & $P$ value $^{\mathrm{a}}$ & Intervention, median $(95 \% \mathrm{CI})$ & $P$ value $^{\mathrm{a}}$ \\
\hline Baseline score & $7.22(6.64$ to 7.81$)$ & $\mathrm{N} / \mathrm{A}^{\mathrm{b}}$ & $7.03(6.46$ to 7.60$)$ & N/A \\
\hline \multicolumn{5}{|c|}{ Difference from baseline } \\
\hline Posttest (1 day) & $0.33(-0.16$ to 0.82$)$ & .14 & $1.00(0.48$ to 1.52$)$ & .001 \\
\hline 1 month & $0.48(-1.13$ to 1.19$)$ & .17 & $1.04(0.35$ to 1.73$)$ & .03 \\
\hline 3 months & $0.63(-0.02$ to 1.27$)$ & .06 & $1.40(0.68$ to 2.12$)$ & .008 \\
\hline 6 months & $0.32(-0.30$ to 0.94$)$ & .27 & $0.88(0.25$ to 1.51$)$ & .144 \\
\hline
\end{tabular}

${ }^{\mathrm{a}}$ Wilcoxon rank sum test for paired data.

${ }^{\mathrm{b}} \mathrm{N} / \mathrm{A}$ : not applicable.

\section{Composite Endpoint of Mortality, Reinfarction, Rehospitalization, and Emergency Room Visits}

No death occurred in the cohort. Five patients visited the emergency room and were subsequently hospitalized. Overall, 7 of $46(15 \%)$ patients ( 2 in the intervention group, 5 in the control group) were hospitalized for cardiovascular reasons (heart rhythm disorders: 1 tachycardia, 1 bradycardia; vagal discomfort: $\mathrm{n}=2$; chest pain that was determined to be noncardiac: $\mathrm{n}=1$; elective stent placement: $\mathrm{n}=1$; and coronary artery bypass grafting: $n=1$ ). No patient had a new infarct during the follow-up period and no difference was observed between groups.

\section{Satisfaction With and Reuse of the Video and Medication Card}

Overall, the patients were highly satisfied with the design, use, and medical content of the video (Figure 5). The majority of patients felt that the video helped them to better understand their disease and medications and indicated that they would recommend it to other patients with ACS. As questions 3 and 4 were negatively worded, some patients may have answered 
them incorrectly. Despite this potential issue, the majority of patients felt comfortable with the interactivity of the video and did not lose the thread of the presentation. Responses regarding whether patients thought they would watch the video again at home were the most mitigated. We found that 18 of $30(60 \%)$ patients viewed the video again at home. The majority of patients strongly appreciated the medication cards, and 22 of $30(73 \%)$ patients reused the cards after discharge.

Figure 5. Patients' satisfaction with the video $(n=28)$.

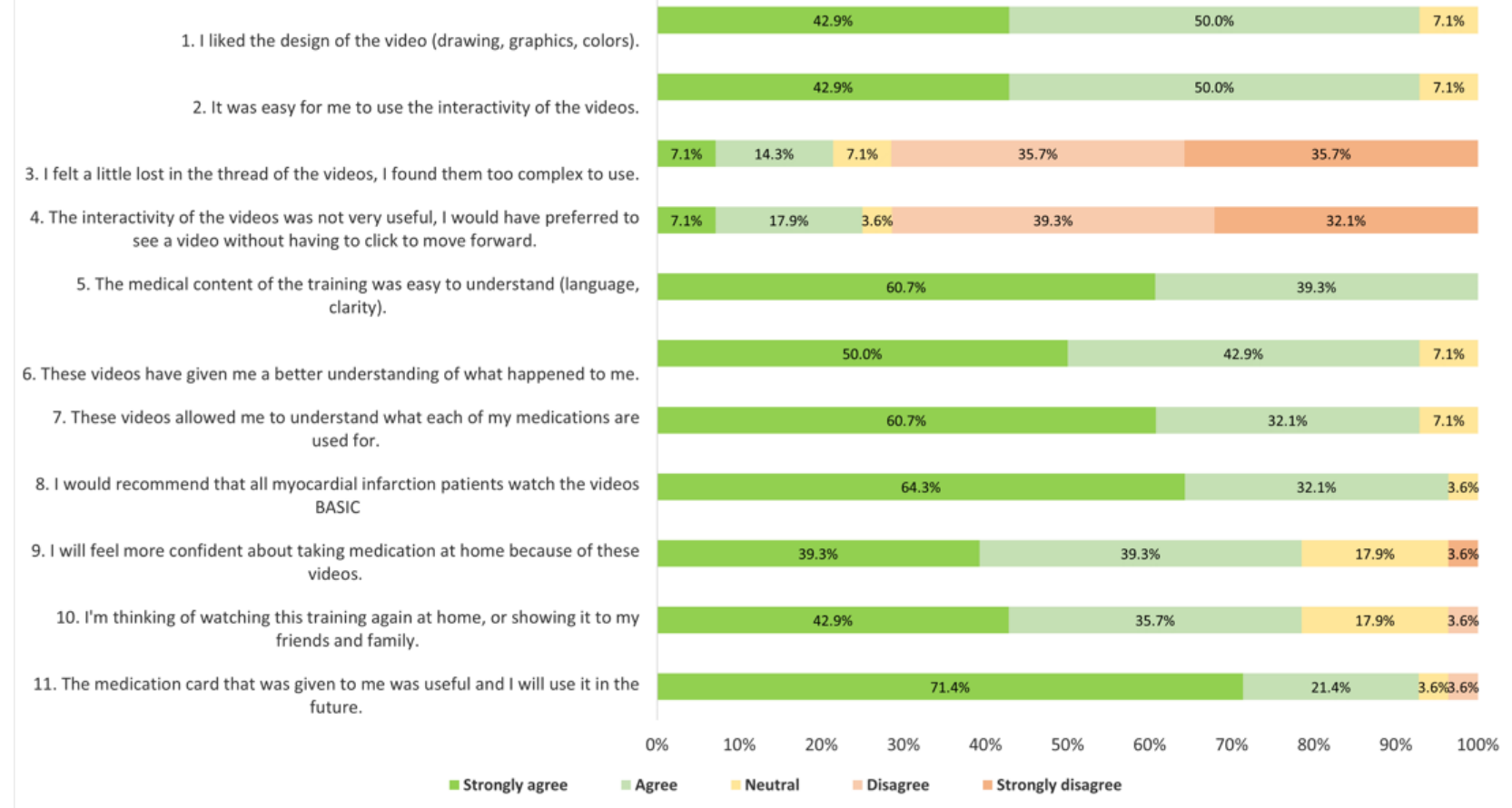

\section{Discussion}

\section{Principal Findings}

The "Mon Coeur, Mon BASIC" web-hosted video seemed to significantly improve the drug adherence of patients with ACS for a few months after treatment initiation: a significant effect was observed at 3 months, but not at 1 or 6 months. Moreover, patients from the intervention group showed significant improvement in their knowledge about ACS and their medications from baseline to 3 months; no such effect was seen in the control group. In addition, patients were generally very satisfied with the information provided in the video and with the medication cards given to them.

The rate of drug adherence was high in both groups at 1 month after ACS. As expected, the median ARMS score tended to increase over time in the control group, reflecting decreasing adherence. At 3 months, the intervention group showed much better drug adherence than did the control group. At 6 months, the median score remained lower in the intervention group, but this difference was not significant. Although the observed trends may not all be attributable to the effect of the video alone, we can state with strong confidence that patients in the intervention group were more likely to refill their prescriptions at 3 months than at 1 month.

In the intervention group, patients' knowledge about ACS and their medications increased significantly from baseline to 1 day (after video viewing) and 3 months after ACS. Thus, the intervention appeared to effectively improve patients' cardiovascular knowledge over the first 3 months after ACS presentation.

Overall, our results are encouraging but must be interpreted with caution. The sample size initially calculated could not be reached, and our study is therefore underpowered. However, our results are still interesting and show a great tendency for improvement of drug adherence and knowledge.

\section{Comparison With Previous Work}

App use has been demonstrated to improve drug adherence. For example, use of the "My Interventional Drug-Eluting Stent Education" app, developed in the United States with a similar goal as the "Mon Coeur, Mon BASIC" video, increased patients' antiplatelet drug adherence and knowledge about PCI in a pilot study [27]. Use of another patient support app increased ticagrelor adherence and tended to improve cardiovascular-related lifestyle changes [28]. mHealth technologies seem to have an impact in drug adherence and should be part of future developments in the cardiology field.

\section{Place of mHealth Technology for ACS Patients}

Most currently available mHealth technologies were developed to support cardiovascular health; products include eHealth diaries [23], apps supporting cardiac rehabilitation [24,25], and complete e-learning platforms [26]. We are convinced that these strategies will make up a large part of future patient care, but their use will likely remain limited for a large proportion of current cardiac patients. The median age of our patients at admission was 59 years, and $20 \%(12 / 60)$ of patients reported low levels of ICT use. Moreover, we had to exclude patients 
with no ICT device or internet connection at home. For these reasons, we sought to develop a tool that is easy to use, even for patients who are not familiar with ICT use. We developed pocket-sized medication cards instead of digital cards for the same reasons, and patients appreciated these cards even more than the video. mHealth cannot replace the face-to-face approach, but it can be used as a complementary tool to increase patients' self-efficacy. In this study, the pharmacist talked with patients and answered their questions after they had watched the video, which may have affected their satisfaction. We will continuously update the content and enhance the interactivity of our web-based video, and we plan to develop a complete app with an easily updated medication plan, a frequently asked questions module, and quizzes to help patients develop even more knowledge.

\section{Limitations}

This study has some limitations. The ARMS is not the gold standard for the assessment of drug adherence; such assessment should include the direct measurement of drug consumption. Unfortunately, patients' drug consumption cannot be determined accurately using data from the Swiss health care system, as drugs are delivered by packs containing a prespecified number of tablets (eg, ticagrelor is available in blister packs of 56 tablets, whereas aspirin is delivered by packs of 98 tablets) and are not delivered by drug unit (for example, 30 tablets for 30 days of treatment). In addition, we did not adjust for some baseline characteristics (eg, age, sex, and educational level), which may have resulted in bias. Nevertheless, all baseline characteristics were similar in the two study groups, which reduced the risk of statistical errors; we thus believe that the intervention had an impact on drug adherence. Another limitation is the small sample, which together with the high degree of variance resulted in the loss of statistical power and the inability to perform subgroup analyses. We had difficulties in recruiting patients because many of them were transferred within 24 hours to a peripheral hospital, and we lost several of them to follow-up. We unfortunately could not continue the recruitment further, and we had to analyze the results with the small sample. The exclusion of patients without home internet access also may have biased the results. Finally, our findings may have been affected by attrition bias, as we lost about $20 \%$ (13/60) of patients between baseline and study completion. Despite these limitations, our results are very encouraging and suggest that the provision of an interactive informational video to patients has positive effects. These results should be confirmed in larger clinical studies that include subgroup analyses to identify the populations that would benefit most from such interventions.

\section{Conclusions}

Despite our study being underpowered, we were still able to show that the "Mon Coeur, Mon BASIC" web-hosted interactive video improved drug adherence and enhanced patients' cardiovascular knowledge. The video will be available at no charge from a webpage constructed by our hospital's cardiology department staff and will be offered to all patients hospitalized for ACS at our institution in the future. Our findings reflect patients' need for and appreciation of medical information; the most appropriate means of providing such information needs to be determined. Such tools should be developed for patients with a wide range of chronic diseases, and their content should be continuously improved. Over time, increasing numbers of patients will be able to use smartphone apps, which provides the opportunity to develop this type of support to improve the management of patients with chronic diseases.

\section{Acknowledgments}

This work was supported by an "e-learning commission" from the University Hospital of Lausanne. The funder had no role in the design of the study; collection, analysis, or interpretation of data; or writing of the manuscript. We sincerely thank all individuals who participated in the development of the "Mon Coeur, Mon BASIC" video, including Alienor Held, Pierre-Antoine Dubois, Ana Loureiro Soares, Anaëlle Morf, and Anne-Sylvie Diezi; we thank Marc Sohrmann for his advice on video content and Laurence Iseli for video narration.

\section{Conflicts of Interest}

None declared.

\section{Multimedia Appendix 1}

Medication card distributed to the intervention group, in addition to the video viewing. [DOCX File, $60 \mathrm{~KB}$-Multimedia Appendix 1]

\section{Multimedia Appendix 2}

ARMS score questionnaire developed by Kripalani et al, with the presentation of the 12 questions and his scoring system. ARMS: Adherence to Refills and Medication Scale.

[DOCX File, 17 KB-Multimedia Appendix 2]

\section{Multimedia Appendix 3}

Questionnaire used for the assessment of the patient's knowledge. Correct answers were evaluated with 1 point and wrong answers with 0 points. Maximal points were 9 points. 


\section{Multimedia Appendix 4}

CONSORT-eHEALTH checklist (V 1.6.1).

[PDF File (Adobe PDF File), 1066 KB-Multimedia Appendix 4]

\section{References}

1. Nichols M, Townsend N, Scarborough P, Rayner M. Cardiovascular disease in Europe 2014: epidemiological update. Eur Heart J 2014 Nov 07;35(42):2929-2933. [doi: 10.1093/eurheartj/ehu378] [Medline: 25381246]

2. Mukherjee D, Fang J, Chetcuti S, Moscucci M, Kline-Rogers E, Eagle KA. Impact of combination evidence-based medical therapy on mortality in patients with acute coronary syndromes. Circulation 2004 Feb 17;109(6):745-749. [doi:

10.1161/01.CIR.0000112577.69066.CB] [Medline: 14970110]

3. Ibanez B, James S, Agewall S, Antunes MJ, Bucciarelli-Ducci C, Bueno H, ESC Scientific Document Group. 2017 ESC Guidelines for the management of acute myocardial infarction in patients presenting with ST-segment elevation: The Task Force for the management of acute myocardial infarction in patients presenting with ST-segment elevation of the European Society of Cardiology (ESC). Eur Heart J 2018 Jan 07;39(2):119-177. [doi: 10.1093/eurheartj/ehx393] [Medline: 28886621]

4. Roffi M, Patrono C, Collet J, Mueller C, Valgimigli M, Andreotti F, ESC Scientific Document Group. 2015 ESC Guidelines for the management of acute coronary syndromes in patients presenting without persistent ST-segment elevation: Task Force for the Management of Acute Coronary Syndromes in Patients Presenting without Persistent ST-Segment Elevation of the European Society of Cardiology (ESC). Eur Heart J 2016 Jan 14;37(3):267-315. [doi: 10.1093/eurheartj/ehv320] [Medline: 26320110]

5. Bruggmann C, Iglesias JF, Gex-Fabry M, Fesselet R, Vogt P, Sadeghipour F, et al. Long-Term Quality of Prescription for ST-Segment Elevation Myocardial Infarction (STEMI) Patients: A Real World 1-Year Follow-Up Study. Am J Cardiovasc Drugs 2020 Feb;20(1):105-115 [FREE Full text] [doi: 10.1007/s40256-019-00361-5] [Medline: 31300969]

6. Melloni C, Alexander KP, Ou F, LaPointe NMA, Roe MT, Newby LK, et al. Predictors of early discontinuation of evidence-based medicine after acute coronary syndrome. Am J Cardiol 2009 Jul 15;104(2):175-181. [doi:

10.1016/j.amjcard.2009.03.013] [Medline: 19576342]

7. Kassab Y, Hassan Y, Abd Aziz N, Ismail O, AbdulRazzaq H. Patients' adherence to secondary prevention pharmacotherapy after acute coronary syndromes. Int J Clin Pharm 2013 Apr 3;35(2):275-280. [doi: 10.1007/s11096-012-9735-y] [Medline: $\underline{23283596}$ ]

8. Kolandaivelu K, Leiden BB, O'Gara PT, Bhatt DL. Non-adherence to cardiovascular medications. Eur Heart J 2014 Dec 07;35(46):3267-3276. [doi: 10.1093/eurheartj/ehu364] [Medline: 25265973]

9. Newby LK, LaPointe NMA, Chen AY, Kramer JM, Hammill BG, DeLong ER, et al. Long-term adherence to evidence-based secondary prevention therapies in coronary artery disease. Circulation 2006 Jan 17;113(2):203-212. [doi: 10.1161/CIRCULATIONAHA.105.505636] [Medline: 16401776]

10. Rasmussen JN, Chong A, Alter DA. Relationship between adherence to evidence-based pharmacotherapy and long-term mortality after acute myocardial infarction. JAMA 2007 Jan 10;297(2):177-186. [doi: 10.1001/jama.297.2.177] [Medline: 17213401]

11. Choudhry NK, Glynn RJ, Avorn J, Lee JL, Brennan TA, Reisman L, et al. Untangling the relationship between medication adherence and post-myocardial infarction outcomes: medication adherence and clinical outcomes. Am Heart J 2014 Jan;167(1):51-58.e5. [doi: 10.1016/j.ahj.2013.09.014] [Medline: 24332142]

12. Mehran R, Baber U, Steg PG, Ariti C, Weisz G, Witzenbichler B, et al. Cessation of dual antiplatelet treatment and cardiac events after percutaneous coronary intervention (PARIS): 2 year results from a prospective observational study. Lancet 2013 Nov 23;382(9906):1714-1722. [doi: 10.1016/S0140-6736(13)61720-1] [Medline: 24004642]

13. Osterberg L, Blaschke T. Adherence to medication. N Engl J Med 2005 Aug 04;353(5):487-497. [doi: 10.1056/NEJMra050100] [Medline: 16079372]

14. Clark PA, Drain M, Gesell SB, Mylod DM, Kaldenberg DO, Hamilton J. Patient perceptions of quality in discharge instruction. Patient Educ Couns 2005 Oct;59(1):56-68. [doi: 10.1016/j.pec.2004.09.010] [Medline: 16198219]

15. Booth K, Beaver K, Kitchener H, O'Neill J, Farrell C. Women's experiences of information, psychological distress and worry after treatment for gynaecological cancer. Patient Educ Couns 2005 Feb;56(2):225-232. [doi:

10.1016/j.pec.2004.02.016] [Medline: 15653253]

16. Prinjha S, Chapple A, Herxheimer A, McPherson A. Many people with epilepsy want to know more: a qualitative study. Fam Pract 2005 Aug;22(4):435-441. [doi: 10.1093/fampra/cmi024] [Medline: 15814581]

17. Murray MD, Young J, Hoke S, Tu W, Weiner M, Morrow D, et al. Pharmacist intervention to improve medication adherence in heart failure: a randomized trial. Ann Intern Med 2007 May 15;146(10):714-725. [doi:

10.7326/0003-4819-146-10-200705150-00005] [Medline: 17502632] 
18. Smith DH, Kramer JM, Perrin N, Platt R, Roblin DW, Lane K, et al. A randomized trial of direct-to-patient communication to enhance adherence to beta-blocker therapy following myocardial infarction. Arch Intern Med 2008 Mar 10;168(5):477-83; discussion 483; quiz 447. [doi: 10.1001/archinternmed.2007.132] [Medline: 18332291]

19. Schwalm J, Ivers NM, Natarajan MK, Taljaard M, Rao-Melacini P, Witteman HO, et al. Cluster randomized controlled trial of Delayed Educational Reminders for Long-term Medication Adherence in ST-Elevation Myocardial Infarction (DERLA-STEMI). Am Heart J 2015 Nov;170(5):903-913 [FREE Full text] [doi: 10.1016/j.ahj.2015.08.014] [Medline: 26542498]

20. Budiman T, Snodgrass K, Komatsu Chang A. Evaluation of Pharmacist Medication Education and Post-discharge Follow-up in Reducing Readmissions in Patients With ST-Segment Elevation Myocardial Infarction (STEMI). Ann Pharmacother 2016 Feb 17;50(2):118-124. [doi: 10.1177/1060028015620425] [Medline: 26681443]

21. Calvert SB, Kramer JM, Anstrom KJ, Kaltenbach LA, Stafford JA, Allen LaPointe NM. Patient-focused intervention to improve long-term adherence to evidence-based medications: a randomized trial. Am Heart J 2012 Apr;163(4):657-65.e1. [doi: 10.1016/j.ahj.2012.01.019] [Medline: 22520532]

22. Agvall B, Alehagen U, Dahlström U. The benefits of using a heart failure management programme in Swedish primary healthcare. Eur J Heart Fail 2013 Feb 27;15(2):228-236 [FREE Full text] [doi: 10.1093/eurjhf/hfs159] [Medline: 23109650]

23. Wolf A, Fors A, Ulin K, Thorn J, Swedberg K, Ekman I. An eHealth Diary and Symptom-Tracking Tool Combined With Person-Centered Care for Improving Self-Efficacy After a Diagnosis of Acute Coronary Syndrome: A Substudy of a Randomized Controlled Trial. J Med Internet Res 2016 Feb 23;18(2):e40 [FREE Full text] [doi: 10.2196/jmir.4890] [Medline: 26907584]

24. Beatty AL, Magnusson SL, Fortney JC, Sayre GG, Whooley MA. VA FitHeart, a Mobile App for Cardiac Rehabilitation: Usability Study. JMIR Hum Factors 2018 Jan 15;5(1):e3 [FREE Full text] [doi: 10.2196/humanfactors.8017] [Medline: 29335235]

25. Frederix I, Hansen D, Coninx K, Vandervoort P, Vandijck D, Hens N, et al. Medium-Term Effectiveness of a Comprehensive Internet-Based and Patient-Specific Telerehabilitation Program With Text Messaging Support for Cardiac Patients: Randomized Controlled Trial. J Med Internet Res 2015 Jul 23;17(7):e185 [FREE Full text] [doi: 10.2196/jmir.4799] [Medline: 26206311]

26. Fontaine G, Cossette S, Heppell S, Boyer L, Mailhot T, Simard M, et al. Evaluation of a Web-Based E-Learning Platform for Brief Motivational Interviewing by Nurses in Cardiovascular Care: A Pilot Study. J Med Internet Res 2016 Aug 18;18(8):e224 [FREE Full text] [doi: 10.2196/jmir.6298] [Medline: 27539960]

27. Shah V, Dileep A, Dickens C, Groo V, Welland B, Field J, et al. Patient-Centered Tablet Application for Improving Medication Adherence after a Drug-Eluting Stent. Front Public Health 2016 Dec 12;4:272 [FREE Full text] [doi: 10.3389/fpubh.2016.00272] [Medline: 28018897]

28. Johnston N, Bodegard J, Jerström S, Åkesson J, Brorsson H, Alfredsson J, et al. Effects of interactive patient smartphone support app on drug adherence and lifestyle changes in myocardial infarction patients: A randomized study. Am Heart J 2016 Aug;178:85-94 [FREE Full text] [doi: 10.1016/j.ahj.2016.05.005] [Medline: 27502855]

29. ELIPS pour combattre l'infarctus et l'athérosclérose. Hôpitaux Universitaires de Genève. 2018. URL: https://www.hug-ge.ch/ elips [accessed 2018-11-01]

30. CHUV service de cardiologie. Mon coeur, mon BASIC, l'essentiel à savoir après un infarctus. 2021 Jan 04. URL: https:/ /www.chuv.ch/video-basic [accessed 2021-04-02]

31. Geneva University Hospitals. Pour combattre l'infarctus du myocarde et l'athérosclérose. 2010 Dec 23. URL: https://www. youtube.com/watch?v=49UUp x30AY [accessed 2021-04-02]

32. Kripalani S, Risser J, Gatti ME, Jacobson TA. Development and evaluation of the Adherence to Refills and Medications Scale (ARMS) among low-literacy patients with chronic disease. Value Health 2009 Jan;12(1):118-123 [FREE Full text] [doi: 10.1111/j.1524-4733.2008.00400.x] [Medline: 19911444]

33. Sousa V, Rojjanasrirat W. Translation, adaptation and validation of instruments or scales for use in cross-cultural health care research: a clear and user-friendly guideline. J Eval Clin Pract 2011 Apr;17(2):268-274. [doi: 10.1111/j.1365-2753.2010.01434.x] [Medline: 20874835]

34. Ousseine YM, Rouquette A, Bouhnik A, Rigal L, Ringa V, Smith, et al. Validation of the French version of the Functional, Communicative and Critical Health Literacy scale (FCCHL). J Patient Rep Outcomes 2017 Feb 7;2(1):3 [FREE Full text] [doi: 10.1186/s41687-018-0027-8] [Medline: 29757319]

35. Harris PA, Taylor R, Thielke R, Payne J, Gonzalez N, Conde JG. Research electronic data capture (REDCap) - A metadata-driven methodology and workflow process for providing translational research informatics support. J Biomed Inform 2009 Apr;42(2):377-381. [doi: 10.1016/j.jbi.2008.08.010]

36. Harris PA, Taylor R, Minor BL, Elliott V, Fernandez M, O'Neal L, REDCap Consortium. The REDCap consortium: Building an international community of software platform partners. J Biomed Inform 2019 Jul;95:103208 [FREE Full text] [doi: 10.1016/j.jbi.2019.103208] [Medline: $\underline{31078660]}$ 


\section{Abbreviations}

ACS: acute coronary syndrome

ARMS: Adherence to Refills and Medication Scale

BASIC: Secondary Prevention of ACS With Beta-Blockers, Antiaggregants, Statins, Angiotensin-Converting Enzyme Inhibitors, and Risk Factor Control

CR: cardio-rehabilitation

FCCHL: Functional, Communicative and Critical Health Literacy

ICT: information and communications technology

mHealth: mobile health

MI: myocardial infarction

NSTEMI: non-ST-segment elevation myocardial infarction

PCI: percutaneous coronary intervention

REDCap: Research Electronic Data Capture

STEMI: ST-segment elevation myocardial infarction

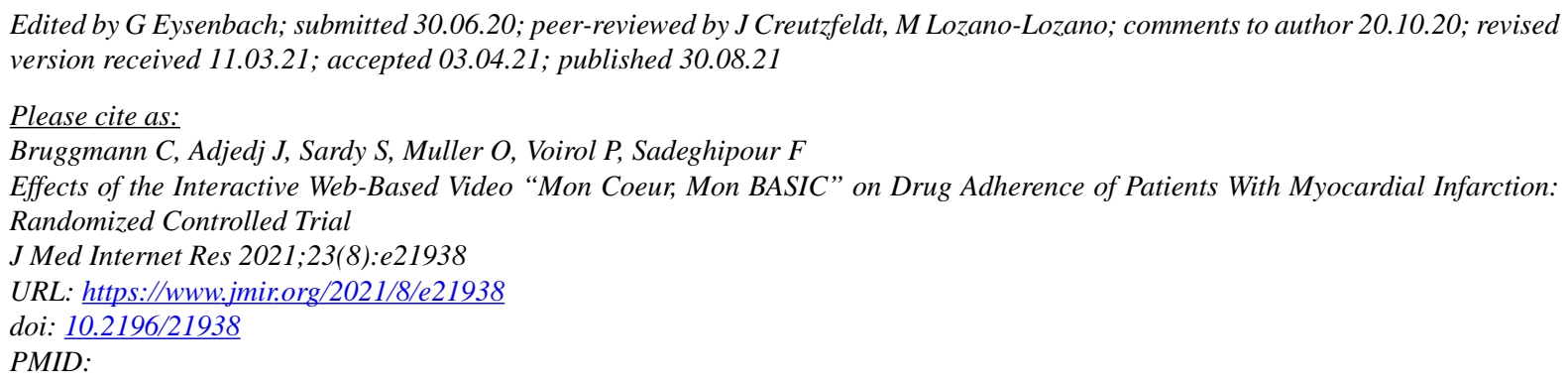

(C)Christel Bruggmann, Julien Adjedj, Sylvain Sardy, Olivier Muller, Pierre Voirol, Farshid Sadeghipour. Originally published in the Journal of Medical Internet Research (https://www.jmir.org), 30.08.2021. This is an open-access article distributed under the terms of the Creative Commons Attribution License (https://creativecommons.org/licenses/by/4.0/), which permits unrestricted use, distribution, and reproduction in any medium, provided the original work, first published in the Journal of Medical Internet Research, is properly cited. The complete bibliographic information, a link to the original publication on https://www.jmir.org/, as well as this copyright and license information must be included. 